\title{
Dentist warns colleagues about PPE dental supply scams
}

A dentist based in Bath has written to the $B D J$ to warn British Dental Association (BDA) members about scams involving dental supply companies taking orders for personal protective equipment (PPE).

Dr Toby Talbot, a Specialist in Restorative Dentistry, writes:

'Recently I made a substantial order for PPE from a dental supply company. I was told only after I had paid for the order that the fees were not refundable. Subsequently, I was informed that the consignment was "damaged" during transit and could not provide me the goods. The supply company has failed to refund my payment despite my request.
'When I was contacted by another "reputable" dental supply company that they had a consignment of PPF3 face masks arriving in 2-3 weeks, once bitten, I was a little more cautious with parting with my money. I specifically asked for the written specification of the masks. They were actually KN95 masks that do not offer my resident oral and maxillofacial surgeon the protection he requires.

'It would seem that even our own established dental supply companies are becoming embroiled in these scams.'

Dr Talbot has not named the agents concerned, but will do so if contacted directly via toby@tobytalbot.co.uk.

\section{Guidelines published to enable confident return to dental practice}

\section{On 1 June 2020 the Faculty of General Dental Practice (UK)} (FGDP $[\mathrm{UK}]$ ) and the College of General Dentistry (CGDent) published the UK Guidelines for a safe return to dental practice during COVID-19 on the FGDP(UK) website.

Implications of COVID-19 for the safe management of general dental practice - a practical guide supports dental professionals to take a risk and evidence-based approach to providing safe general dental care in the current circumstances and allows the flexibility of setting minimum requirements whatever the national COVID-19 threat level.

The guidance has been developed as a framework to enable the confident return to practice, now and also into the future as the situation with COVID-19 continues to evolve.

In line with other FGDP(UK) Guidance and Standards publications, the guidance adopts the $\mathrm{ABC}$ (Aspirational, Basic, Conditional) approach to measures with 'basic' measures being a minimum standard.

The guidance is divided into five sections - four of which reflect the patient journey - and the fifth concerns general management of the practice. These sections are assigned a risk status and ABC-based risk mitigation measures to ensure safe practice. The guidance is available at: https://www.fgdp.org.uk/implications-covid-19-safemanagement-general-dental-practice-practical-guide.

\section{Notices of death}

\section{Frederick Alan Smedley}

It is with sadness that we record that Frederick Alan Smedley passed away from leukaemia on 8 April 2020.

\section{Graham McKirdy}

We are sad to report the death of Graham McKirdy of Glasgow, on Sunday 3 May 2020.

\section{Key questions remain over the re-opening of dental services}

On 28 May the British Dental Association (BDA) welcomed news the government has given the green light for the restoration of routine care services in England, but has cautioned that practices will need to move at different rates depending on availability and fitting of PPE, their ability to enact ongoing social distancing measures and time to implement appropriate cross-infection control.

NHS England and the Chief Dental Officer confirmed that any practice that feels it is appropriately prepared could provide patient care from 8 June. This could see varying levels of treatments made available with immediate effect, with individual practitioners exercising their professional judgement on the pace of change.

The pace at which patient care begins will be determined by a number of issues, such as stock levels of PPE. The availability of, and ability to fit test, 'higher end' PPE in particular may limit the universal restoration of a full range of dental care. The BDA has expressed the view that steps should be taken to integrate dentistry into the wider government strategy on PPE supply led by Lord Deighton.

Dentist leaders have also warned the whole business model that the service is based on could change unalterably upon reopening, with social distancing and cross-infection control reducing capacity and potentially access levels by as much as two thirds.

The BDA is continuing to press for the NHS contractual framework to reflect the new reality and for additional support for private dentistry, including a business rates holiday - already offered to leisure and retail sectors - to be expanded to dental practices, alongside other support to mitigate against reduced patient numbers.

BDA Chair Mick Armstrong said: 'A return of high street dentistry will be welcome news to millions of patients left with few options during lockdown, but key questions remain.

'It is right to allow practices to decide themselves when they are ready to open. Dentists will be keen to start providing care as soon as safely possible, but we will need everyone to be patient as practices get up and running.' 